\title{
Functional Cooperation Between Topoisomerase I and Single Strand DNA-binding Protein
}

\author{
Devanjan Sikder, Shyam Unniraman, Tisha Bhaduri \\ and Valakunja Nagaraja*
}

Department of Microbiology and Cell Biology, Indian

Institute of Science, Bangalore 560012, India

\begin{abstract}
Protein-protein interactions play important role in cell biochemistry by favorably or adversely influencing major molecular events. In most documented cases, the interaction is direct between the partner molecules. Influence of activity in the absence of direct physical interaction between DNA transaction proteins is another important means of modulation. We show here that single strand binding protein stimulates DNA topoisomerase I activity without direct protein-protein interactions. The stimulation is specific to topoisomerase I, as DNA gyrase activity is unaffected by SSB. We propose that such cases of functional collaboration between DNA transaction proteins play important roles in vivo.
\end{abstract}

Keywords: Gyrase; topoisomerase 1; single strand binding protein; functional cooperation

\section{Introduction}

DNA topoisomerases constitute a group of enzymes that change the topology of the DNA by breaking and resealing the phosphodiester backbone of DNA. These functions of topoisomerases are of vital importance in regulating major macromolecular events. Both prokaryotes and eukaryotes have been shown to possess more than one topoisomerase, possibly evolved to provide division of labor and in certain cases as backup strategies to take care of important cellular functions. ${ }^{1,2}$ The enzymes are mainly divided into two classes based on the differences in reaction mechanisms. Type I enzymes effect topological changes in DNA by transiently cleaving one DNA strand at a time, allowing the passage of another strand followed by religation, leading to a change in the linking number of DNA in single steps. ${ }^{3}$ The second class of enzymes (type II topoisomerases) introduce transient double strand breaks, allowing the passage of the intact duplex, and then rejoining the broken duplex changing the linking number in

Abbreviations used: EcoSSB, E.coli SSB; EcoTop, E.coli topoisomerase I; EMSA, electrophoretic mobility shift assay; MsTop, Mycobacterium smegmatis topoisomerase I; MtubSSB, Mycobacterium tuberculosis SSB; SSB, single strand DNA binding protein; STS, strong topoisomerase I site.

E-mail address of the corresponding author: vraj@mcbl.iisc.ernet.in steps of two. Both types of enzymes participate in nearly all cellular transactions and play a role to maintain the chromosomal superhelical density in vivo. Homeostatic control of superhelicity of DNA in the cell is achieved by the contrasting actions of DNA topoisomerase I and DNA gyrase.

Topoisomerases have been studied from diverse organisms ranging from Escherichia coli to humans. ${ }^{4}$ These studies have led to the understanding of biochemical properties, domainal organization and the mechanism of action of this important class of enzymes. It is becoming increasingly evident that the in vivo function of topoisomerases is subjected to modulation by other proteins. For instance, Saccharomyces cerevisiae SGS1 protein, a helicase, has been shown to interact with topoisomerase II. ${ }^{5}$ The protein was shown to interact with the putative leucine zipper region of topoisomerase II and was proposed to assist in the decatenation reaction. SGS1 also interacts with topoisomerase III, and the physical association between the two proteins seems to function in chromosomal segregation. ${ }^{6}$ In a similar way, Pat1, a protein important for chromosome transmission in $S$. cerevisiae, was found to associate with topoisomerase II. ${ }^{7}$ Furthermore, p53 is shown to contact human topoisomerase I and modulates its activity. ${ }^{8}$ The recent finding of a gyrase inhibitory protein, GyrI, indicates the existence of such modulatory proteins in the prokaryotic kingdom. ${ }^{9}$

DNA replication is a major molecular event in the cell that requires an orchestrated participation 
of a large number of DNA transaction proteins. Amongst others, DNA polymerases, helicases, single strand binding protein (SSB), topoisomerases, primases, ligase, $\beta$-sliding clamp, clamp loaders and replication terminator protein play a decisive role in the events during various stages of replication. Considering their important intracellular functional assignment, it is not surprising that many of these proteins should interact with one another. Studies aimed in this direction have provided evidence for physical interaction in many instances. SSB has been shown to play an important role at the primosome assembly site. ${ }^{10}$ After the primer is made, the $\chi$-SSB complex displaces the primase, thereby setting the stage for DNA polymerase III to extend the nascent DNA chain. ${ }^{11}$ Interaction of DnaG protein with host SSB at the G4ori site is prerequisite during G4 replication initiation. ${ }^{12}$ Direct protein-protein interaction is necessary between DnaG primase and DnaB helicase for optimal primer synthesis. ${ }^{13}$ In turn, DnaB helicase-replication terminator protein interaction seems to be required for termination of DNA replication. ${ }^{14}$

Furthermore, there are many instances of interaction between proteins primarily involved in replication with those in other cellular processes, thereby establishing a link between diverse cellular events. SSB is one major component of the replication machinery that interacts with many proteins, catalyzing a variety of cellular functions. For instance, SSB interacts with $\mathrm{RecO}$ and RecBCD, both components of the homologous recombination pathway. ${ }^{15,16}$ SSB also modulates the RecA function in E. coli by destabilizing secondary structures in the substrate DNA. ${ }^{17}$ The MucB protein has also been shown to interact with SSB directly. This interaction is proposed to play a critical role in SOS regulated mutagenesis. ${ }^{18}$ These findings imply a more significant role for SSB than previously envisaged.

Although DNA topoisomerases play an important role in the replication process, interaction of this group of enzymes with other components of the replication machinery is not well understood. Here, we have considered the interaction of SSB with DNA topoisomerase I and DNA gyrase. While DNA gyrase activity is unaffected, topoisomerase I activity is stimulated by SSB from heterologous sources. Our results highlight the importance of functional collaboration in the modulation of protein activity in the absence of direct association between the proteins.

\section{Results}

\section{Stimulation of DNA relaxation activity of two different type I topoisomerases}

We investigated the effect of E. coli SSB (EcoSSB) on DNA relaxation activity of the topoisomerase I from two different sources (Figure 1). DNA relaxation activity of both mycobacterial (Figure 1(a)) and E. coli (Figure 1(b)) enzyme is stimulated in the presence of EcoSSB. Maximum stimulation of relaxation activity of Mycobacterium smegmatis topoisomerase I (MsTop) was observed when $1000 \mathrm{fmol}$ of SSB was used (Figure 1(a)). Further increase in SSB resulted in gradual inhibition of relaxation. The stimulation of DNA relaxation activity of EcoTop was seen in the presence of 6.7 to 33-fold molar excess of EcoSSB with respect to DNA (Figure 1(b), lane 8). Assuming a binding site of $32 \mathrm{nt}$, the substrate DNA would be expected to 4 to $20 \%$ saturated with SSB at this range of concentration.

\section{Stimulation of cleavage activity of mycobacterial topoisomerase I by SSB}

The reaction mechanism of DNA relaxation by type I A topoisomerases can be dissected into several discrete steps. Initially, the enzyme binds DNA non-covalently, followed by the nicking of one of the strands of DNA, concomitant reaches with the formation of $5^{\prime}$-phosphotyrosine covalent enzyme-DNA adduct. Subsequently, the intact DNA strand is passed through the nick followed by the regeneration of the phosphodiester bond at the site of nick, with the simultaneous release of the enzyme from the covalent complex. We have previously identified the strong topoisomerase sites (STS) for MsTop. ${ }^{19}$ To determine whether SSB was acting at a step prior to cleavage, we assessed the formation of the covalent MsTop-DNA complex in the presence of SSB as described in Materials and Methods. Mycobacterial SSB (MtubSSB) stimulated the covalent complex formation by about threefold (Figure 2). Further increase in SSB concentration inhibited the reaction (Figure 2(a), lanes 7 and 8), and the complex formation is abolished at the highest concentration of SSB tested (Figure 2(a), lane 9). Similar results were obtained when EcoSSB was used to assess the covalent complex formation with MsTop (Figure 2(b)) under identical experimental condition. The maximum stimulation obtained with mycobacterial and EcoSSB was comparable.

\section{Effect of SSB on non-covalent DNA binding}

Stimulation of DNA cleavage activity of topoisomerase I could be an indirect result of enhanced DNA binding or because of improved catalysis itself. Therefore, we tested the effect of SSB on DNA binding. Electrophoretic mobility shift assay is a convenient method to assess non-covalent complex formation. The assay would also allow the assessment of direct protein-protein interaction (if any) between topoisomerase I and SSB as shown in case of DnaG protein and SSB. ${ }^{12}$ In these experiments, supershifted complex was observed with G4ori-SSB-primase. In another set of experiments, the mobility of SSB-DNA nucleoprotein complex was altered in presence of MucB. ${ }^{18}$ When end-labeled STS containing oligonucleotide was 
(a)

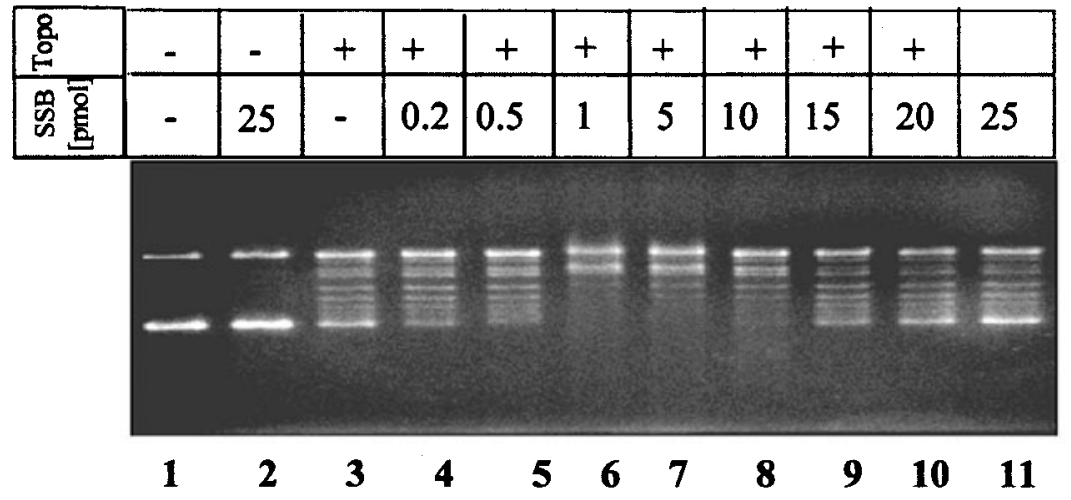

(b)
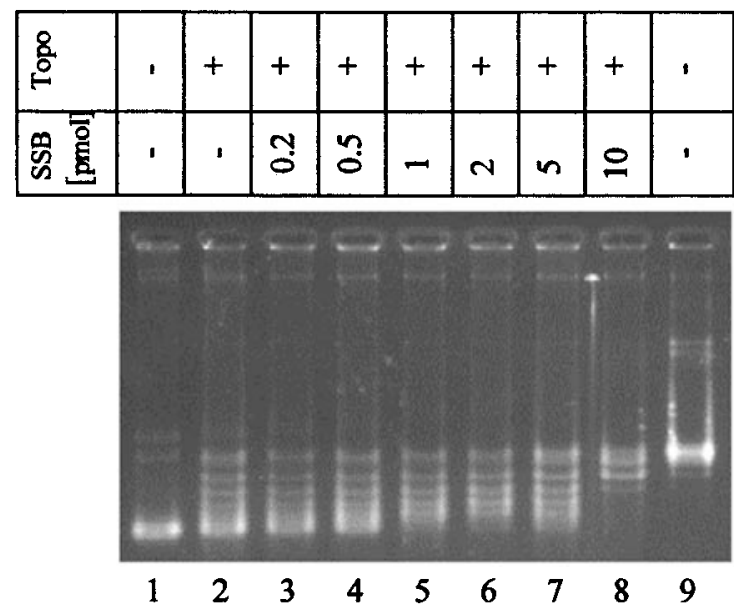

Figure 1. Influence of SSB on topoisomerase I DNA relaxation activity. Reactions were carried out at $37^{\circ} \mathrm{C}$ for 30 minutes as described in Material and Methods. Samples were resolved on $1.2 \% \quad(\mathrm{w} / \mathrm{v})$ agarose gel. The DNA was visualized under UV after staining with ethidium bromide. (a) Effect on mycobacterial topoisomerase I. Lane 1, supercoiled pUC18; lane 2, supercoiled pUC18 incubated with 25,000 fmol of EcoSSB; lanes 3-11, supercoiled pUC18 incubated with 0.5 units of MsTop in the presence of EcoSSB as indicated. (b) Effect on E. coli topoisomerase I. Lane 1, supercoiled pUC18; lane 9, relaxed pUC18; lanes 2-8, supercoiled pUC18 incubated with 0.5 units of EcoTop in the presence of EcoSSB as indicated. incubated with EcoSSB (Figure 3(a), lane 2) and MsTop (lane 3), distinct complexes corresponding to EcoSSB-DNA and topoisomerase-DNA complex were formed but no supershifted complex was detected. Pre-incubation of DNA with MsTop (Figure 3(b)) or co-incubation with EcoSSB and MsTop did not alter the results. In all these experiments, irrespective of the order of addition, EcoSSB stimulated the formation of the topoisomerase-DNA complex (Figure 3(a) and (b)), compare lanes 3 to 6). A five- to tenfold increase in EcoSSB concentration interfered with the formation of the topoisomerase-DNA complex. A further increase totally inhibited the DNA binding activity of topoisomerase I (Figure 3(c)). A specific signature complex of either SSB or topoisomerase I with DNA is observed at higher concentration of these proteins. From the data, it is clear that more SSB is required to displace topoisomerase I, reflecting higher affinity of topoisomerase I to DNA. The SSB, in general, seemed to have lower affinity to DNA (see below). Very similar results were obtained when MtubSSB was used (instead of EcoSSB) along with MsTop in EMSA experiments (data not shown). A supershifted complex is not observed under any set of experimental conditions (Figure 3, unpub- lished results). Next, we investigated the topoisomerase I-DNA complex formation at a fixed SSB and varying concentrations of topoisomerase I. This would further assess the role of SSB in stimulation of topoisomerase I activity. The results are presented in Figure 4. At the concentrations of topoisomerase I used, SSB stimulated the complex formation. It appears, from all these results, that the stimulation of topoisomerase I relaxation activity by SSB is not mediated by direct interaction between the two proteins. Stimulation of topoisomerase I-DNA complex formation and activity in experiments described above by heterologous SSB strengthens this interpretation (see Discussion). On the other hand, it is likely that SSB alters the topology of the DNA duplex and thereby facilitates the binding of topoisomerase I.

\section{SSB alters DNA topology}

To analyze the untwisting activity of SSB on the DNA duplex, we performed ligation in the presence of different amounts of SSB and the products were resolved after removing the proteins. In the absence of SSB, phage T4 DNA ligase converted linear pUC18 (Figure 5, lane 2) into a slower mov- 
(a)

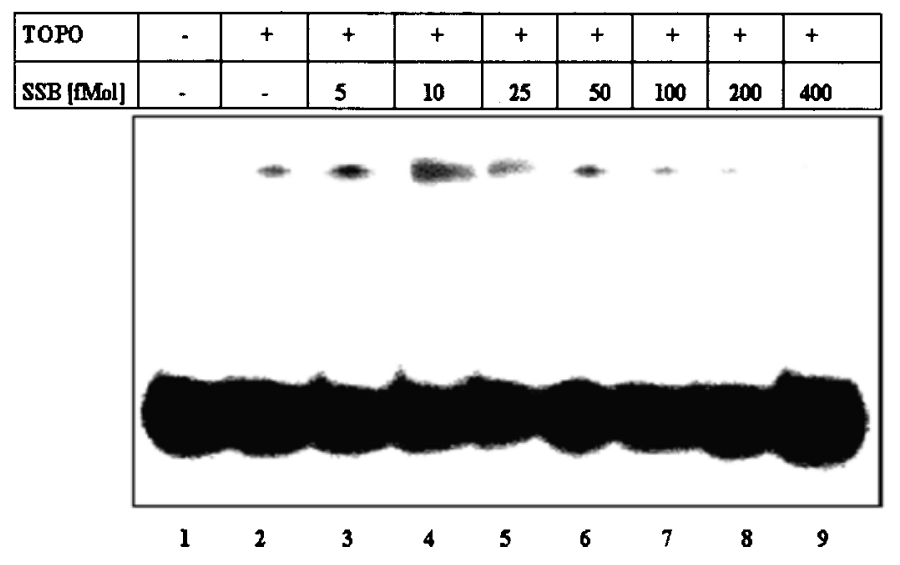

(b)

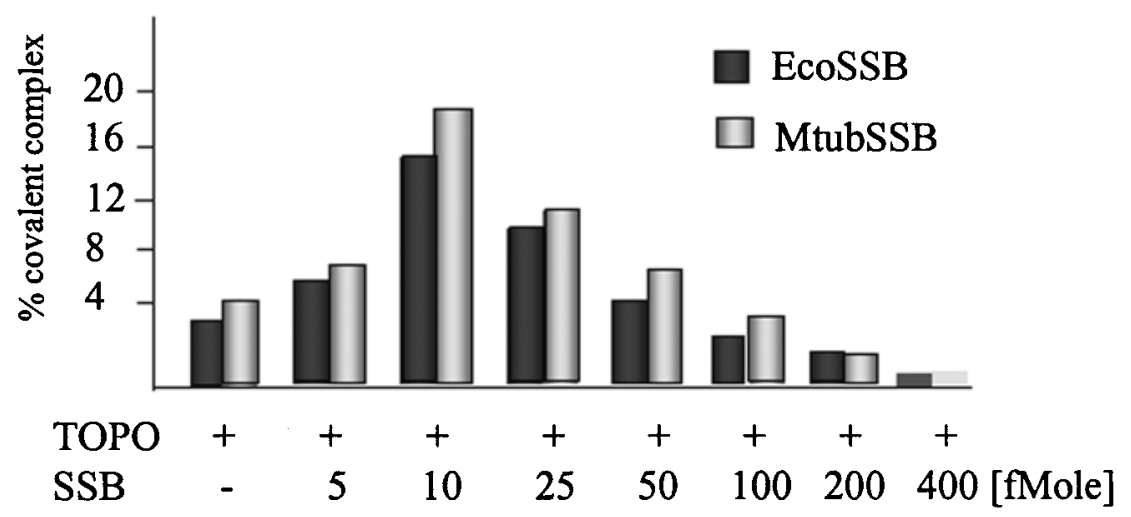

Figure 2. SSB stimulates the covalent complex formation. (a) End-labeled $65 \mathrm{bp}$ Hinfl fragment was incubated with indicated amounts of MtubSSB (lanes, 2-9) and $10 \mathrm{fmol}$ of MsTop (lanes 2-9). (b) Comparative stimulation of covalent complex formation by mycobacterial and E. coli SSB. ing relaxed form (Figure 5, lane 3). In the presence of SSB (Figure 5, lanes 4 and 5), more underwound products were formed in a concentrationdependent manner. These results are in agreement with SSB-mediated untwisting of DNA demonstrated earlier. ${ }^{20}$ Thus, it is possible that topoisomerase $\mathrm{I}$ is preferentially recruited to the regions melted by SSB. In agreement with this, the SSB mediated stimulation of topoisomerase binding to the duplex is comparable to the binding of topoisomerase in the single-stranded context (Figure 4).

\section{Topoisomerase I does not directly interact with SSB}

Electrophoretic mobility shift assays (Figure 3) indicated the absence of direct interaction between topoisomerase I and SSB. However, considering the limitations of the technique we resorted to gel filtration analysis of the two proteins from same source (Figure 6). Topoisomerase I and SSB from E. coli were individually loaded onto the column and the elution pattern obtained was compared to the profile when both proteins were loaded after co-incubation. The assays were performed at two different ionic conditions, $50 \mathrm{mM}$ and $150 \mathrm{mM}$. One representative pattern is shown in Figure 6(a). SDS-PAGE analysis (Figure 6(b)) of the profile shows the elution of two proteins at different fractions. Identical elution pattern of the two proteins was observed at two different ionic conditions. Similar gel filtration analysis with MsTop and SSB also did not reveal any physical association between the proteins. In addition to the above experiments, we carried out immunoprecipitation (Figure 7(a)) and glutaraldehyde crosslinking experiments (Figure 7(b)) to address the physical interaction between topoisomerase I and SSB. When co-incubated, SSB and topoisomerase I were subjected to immunoprecipitation using topoisomerase I-specific antibody. SSB was detected only in supernatant (Figure 7(a), lane 3). In a similar way, crosslinking experiments failed to detect interaction between the two proteins. True to their subunit structure, topoisomerase I and SSB migrate as monomer and tetramer, respectively, after crosslinking (Figure 7(b), lane 6). To further substantiate these findings, we resorted to SPR 
(a)

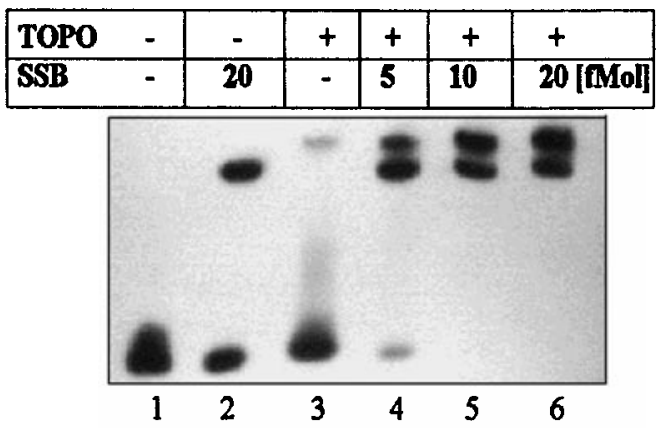

(b)

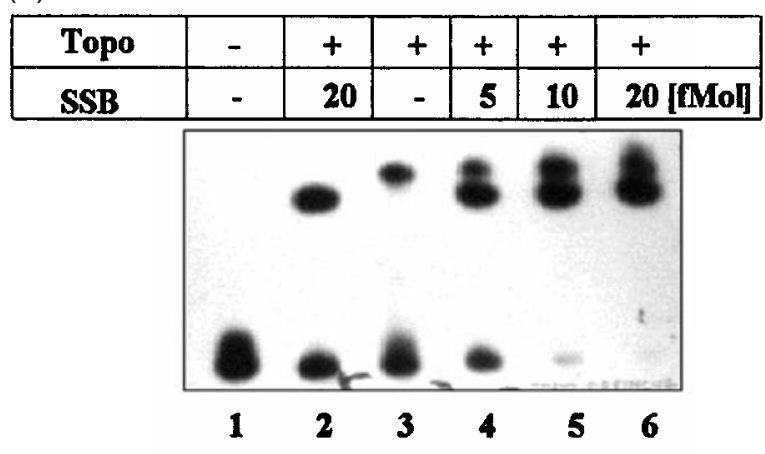

(c)

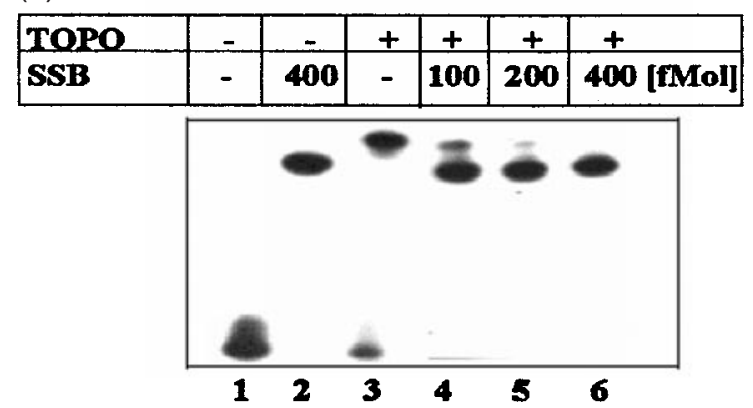

Figure 3. Effect of SSB on DNA binding. (a) SSB preincubation: end-labeled double-stranded 32mer oligonucleotide was incubated for five minutes in the presence of varying amounts of EcoSSB as indicated. A $10 \mathrm{fmol}$ sample of MsTop was added to the EcoSSB-DNA complex (lanes 3-6). (b) Topoisomerase pre-incubation: endlabeled double-stranded oligonucleotide (lane 1) was incubated with MsTop (lanes 3-6). The formed complex was thereafter incubated with EcoSSB where indicated. (c) Effect of high SSB concentration: end-labeled oligonucleotide was incubated with $400 \mathrm{fmol}$ of EcoSSB (lane 2), $10 \mathrm{fmol}$ of MsTop (lane 3) or with both EcoSSB (100, 200 and $400 \mathrm{fmol}$ ) and 10 fmoles of topoisomerase I (lanes, 4, 5 and 6, respectively). Lane 1 has the free DNA control.

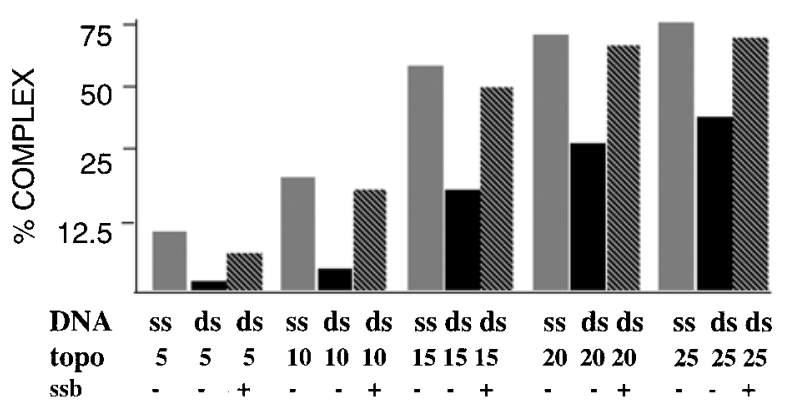

Figure 4. SSB stimulates topoisomerase I-DNA interaction. Comparison of complex formation in the presence and absence of SSB with increasing concentrations of topoisomerase I is depicted. EMSA carried as described in Materials and Methods, after incubating $10 \mathrm{fmol}$ of SSB, indicated amounts of topoisomerase I and $0.1 \mathrm{pmol}$ of single or double strand end-labeled DNA. The autoradiograms were scanned using BIORAD GS-710 densitometer.

analysis, a sensitive way of measuring direct interactions. SPR measurements provide a real-time evaluation of the interaction between two proteins. The technique has been used to demonstrate the direct interaction of the $\chi$ subunit of DNA polymerase III and SSB. ${ }^{11}$ Surface plasmon resonance studies have also been used to demonstrate physical interaction between ICP8, an SSB homologue in herpes simplex virus, and the primosome. ${ }^{21}$ Initially, MsTop and EcoTop (22.5-500 nmol) were passed over MtubSSB immobilized on a carbooxymethyldextran (CM5) chip. There was no net change in resonance units, suggesting the absence of physical interaction between the two proteins. The immobilized SSB, however, could bind to the oligonucleotide when passed over the biosensor chip. The fact that the immobilized SSB was active was further substantiated by its ability to interact with uracil DNA glycosylase. ${ }^{22}$ Since both the SSB and topoisomerase I are DNA-binding proteins, we investigated the possibility of their interaction in the presence of DNA. SPR analyses were carried out using the 24-bp biotinylated oligonucleotides with the recognition sequence for MsTop. ${ }^{19}$ Varying concentrations of MsTop were passed over the immobilized oligonucleotide on the SA5 sensor chip. A rapid increase in the RU as a function of time reflects the changes in mass during the association phase. Evaluation of the sensogram data yields $k_{1}$ and $k_{-1}$ for the interaction of MsTop with the DNA as $3.7 \times 10^{5} \mathrm{M}^{-1} \mathrm{~s}^{-1}$ and $8.6 \times 10^{-4} \mathrm{~s}^{-1}$, respectively (Table 1$)$. The binding constant $\left(K_{\mathrm{a}}\right)$ and the dissociation constant $\left(K_{\mathrm{d}}\right)$ were $4.3 \times 10^{8}$ and $2.3 \times 10^{-9}$, respectively. Subsequently, when MtubSSB was injected (Figure 7(a)) after the formation of binary complex between DNA and MsTop, no appreciable change in the resonance was detected. Similar results were obtained when MsTop was passed after MtubSSB was bound to the oligonucleotide (Figure 7(b) and Table 1). In another set of experiments, the probable interaction 
Table 1. Kinetic and equilibrium parameters of DNA binding of topoisomerase I and SSB

\begin{tabular}{|c|c|c|c|c|c|c|}
\hline $\begin{array}{l}\text { Protein } \\
\text { Immobilized on } \\
\text { DNA }\end{array}$ & $K_{\mathrm{a}}(1 / \mathrm{Ms})$ & $\begin{array}{c}K_{\mathrm{d}} \\
\text { (1/second) }\end{array}$ & $K_{\mathrm{A}}(1 / \mathrm{M})$ & $K_{\mathrm{D}}(\mathrm{M})$ & $\begin{array}{l}\text { Protein in } \\
\text { mobile phase }\end{array}$ & $\begin{array}{c}\text { Change in } \\
\text { RU }\end{array}$ \\
\hline MsTop & $3.7 \mathrm{e} 5$ & $8.6 e-4$ & $4.3 \mathrm{e} 8$ & $2.3 e-9$ & \multirow{4}{*}{$\begin{array}{l}\text { (a) EcoSSB } \\
\text { (b) MtubSSB } \\
\text { (a) EcoSSB } \\
\text { (b) MtubSSB } \\
\text { (a) EcoTop } \\
\text { (b) MsTop } \\
\text { (a) EcoTop } \\
\text { (b) MsTop }\end{array}$} & NC \\
\hline EcoTop & $1.8 \mathrm{e} 5$ & $1.1 \mathrm{e}-3$ & $1.6 \mathrm{e} 8$ & $6.2 \mathrm{e}-9$ & & NC \\
\hline MtubSSB & $6.8 \mathrm{e} 4$ & $8.6 e-4$ & $8 \mathrm{e} 7$ & $1.3 e-8$ & & $\mathrm{NC}$ \\
\hline EcoSSB & $9 \mathrm{e} 3$ & $1.1 \mathrm{e}-4$ & $8 \mathrm{e} 7$ & $1.2 \mathrm{e}-8$ & & NC \\
\hline
\end{tabular}

NC, no change.

of EcoTop and EcoSSB was investigated. Varying concentrations of EcoTop and EcoSSB were individually passed first, and the kinetic and equilibrium parameters governing the interaction between DNA-topoisomerase I and DNA-EcoSSB were obtained (Table 1). These results were comparable to their mycobacterial counterpart (Table 1). When EcoSSB was passed over the pre-formed binary complex of EcoTop-DNA, the proteins failed to interact (Figure 7(c)). Similar results were obtained when EcoTop was passed over the EcoSSB-DNA complex (Figure 7(d)), thus corroborating the results obtained in the preceding experiments and confirming the absence of direct protein-protein interaction between the two proteins.

\section{DNA gyrase activity is not stimulated by SSB}

Since the stimulation mediated by SSB is independent of direct protein-protein contact, we wanted to analyze the effect of SSB on other topoisomerization reactions. DNA gyrase is the sole supercoiling activity that plays a crucial role to relieve the accumulation of positive supercoils

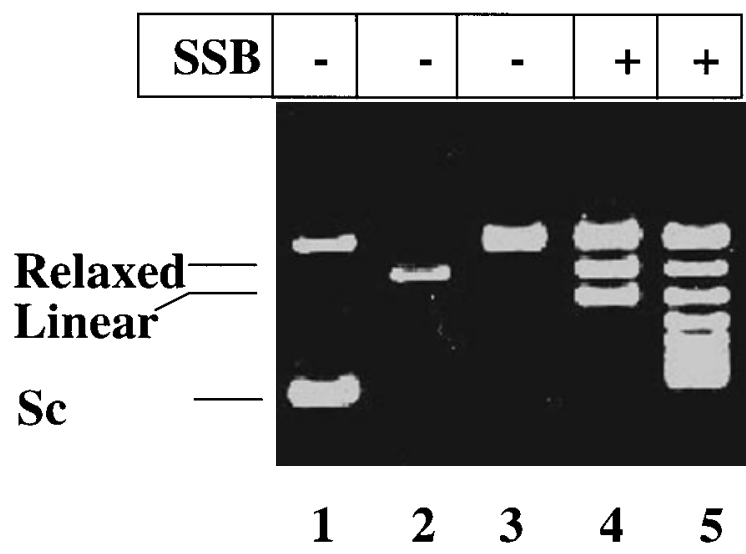

Figure 5. Influence of SSB on DNA topology. pUC (330 $\mathrm{ng}$, lane 1) was linearized by restriction digestion (lane 2). Linearized DNA was ligated using T4 DNA ligase ( 3 units) at $25^{\circ} \mathrm{C}$ for eight hours either in the absence (lane 3 ) or in the presence of indicated amounts of SSB. The reaction products were processed as described in Materials and Methods. ahead of DNA tracking machines, including the replication fork. In addition, under appropriate conditions, gyrase can perform a variety of topoisomerization reactions. For example, in the absence of ATP it can relax negatively supercoiled DNA. Over the entire range of EcoSSB concentration tested here (200 to $10,000 \mathrm{fmol})$, there was no discernable effect on the relaxation mediated by E. coli DNA gyrase (Figure 7(a)). Thus, the SSB mediated

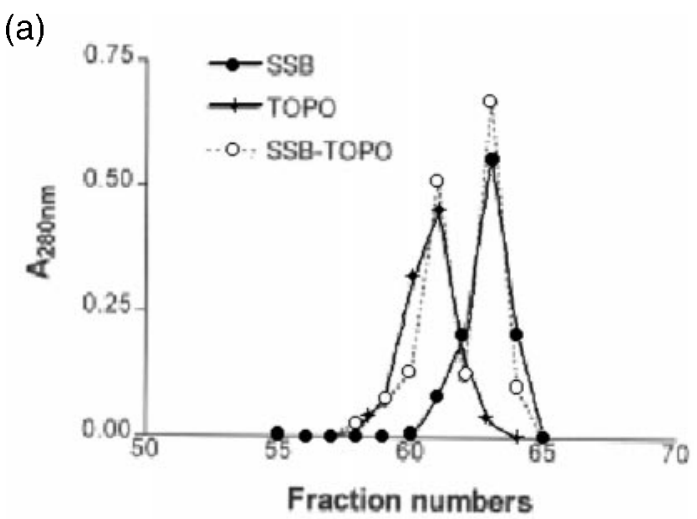

(b)

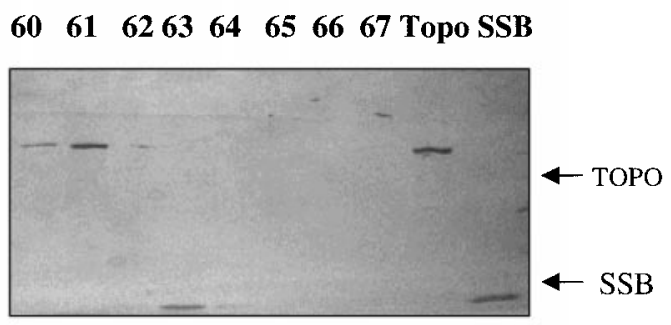

Figure 6. Gel filtration assay. EcoSSB (filled circles), EcoTop (asterisk), or EcoSSB and EcoTop (open circles) were incubated as described in Materials and Methods, in the presence of $150 \mathrm{mM} \mathrm{NaCl}$ and loaded on a Superdex 200 gel filtration column. (a) Graphical representation of the elution profile. (b) Fractions of $200 \mu$ l were collected from the third gel filtration experiment where co-incubated SSB-topoisomerase mixture is loaded and analyzed by SDS-8\% PAGE. 


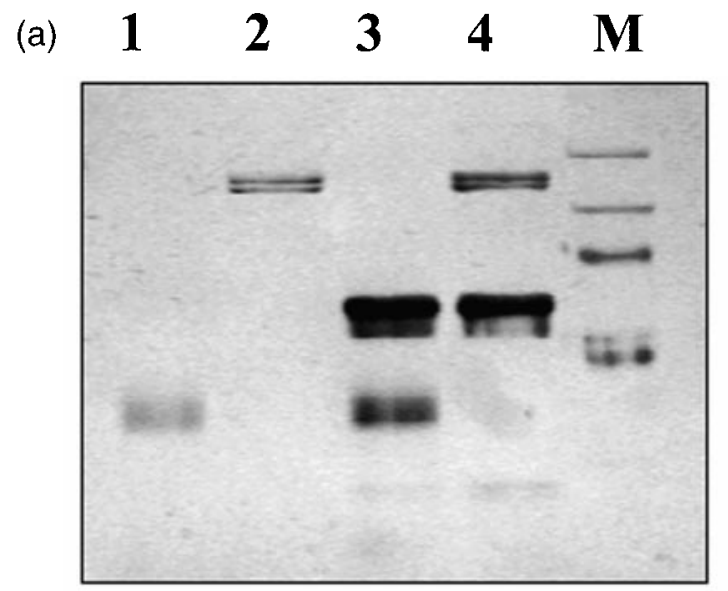

(b)

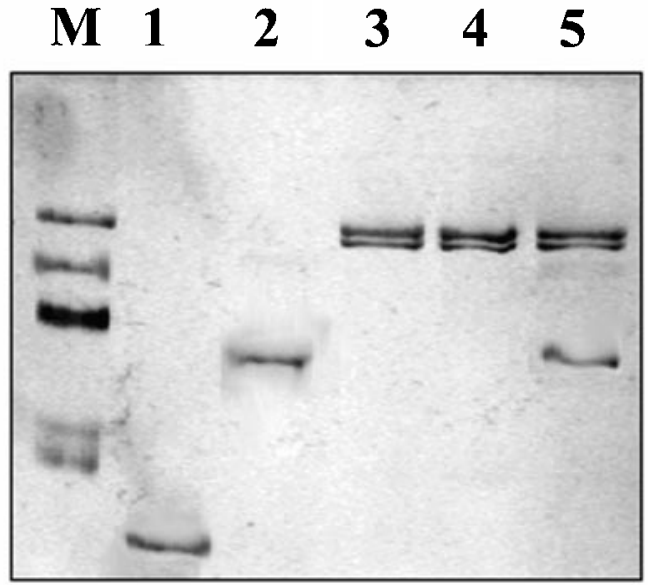

Figure 7. Absence of physical interaction between topoisomerase I and SSB. (a) Immunoprecipitation. MtbSSB and MsTop were either directly loaded (lanes 1 and 2, respectively) or coincubated, immunoprecipitated and processed as described in Materials and Methods. Supernatent (lane 3) and pellet (lane 4) after immnoprecipitation. Lane 5 is molecular mass marker, 116, 98, 76, 29 and $20 \mathrm{kDa}$, respectively. (b) Gluteraldehyde crosslinking. Lane 1 molecular mass markers, as described above; lane 2, MtbSSB alone; lane 2, MtbSSB + glutaraldehyde; lane 4, MsTop alone; lane 5, MsTop + glutaraldehyde; lane 6, SSB and topoisomerase I coincubated and treated with glutaraldehyde.

stimulation is specific to the relaxation reaction of topoisomerase I. Similarly, there was no detectable modulation of the supercoiling activity of the enzyme by SSB (Figure 7(b)).

\section{Discussion}

In this manuscript we demonstrate the importance of functional cooperation between two proteins involved in DNA transaction process. SSB, irrespective of its source, is shown to stimulate the enzymatic action of topoisomerase I, without involving direct protein-protein interactions. While the former is a single strand structure maintenance protein, the latter catalyzes the breakage and religation of covalent bonds altering the physical properties of DNA. SSB-mediated stimulation of DNA relaxation activity is restricted to topoisomerase I and does not extend to all topoisomerases.

SSB affects DNA transactions by either of two ways: (i) direct protein-protein interaction, e.g. interactions of SSB with Primase, ${ }^{11,12} \chi$-subunit of DNA polymerase III; ${ }^{11}$ RNA polymerase, ${ }^{23}$ exonuclease I protein, ${ }^{24} \mathrm{RecO}^{15,25}$ and $\mathrm{MucB}^{, 18}$ and (ii) by binding single-stranded DNA and thereby modulating the function of another protein, e.g. RecBCD, ${ }^{16} \operatorname{RecA}^{26}$ and DNA helicases. ${ }^{27}$ In the second mode of interaction, its action could be mediated by influencing topology of DNA. ${ }^{28,29}$ SSB could affect the topological state of the DNA by influencing the function of topoisomerase I or DNA gyrase either by establishing a direct contact or by cooperating functionally. The enhanced DNA supercoiling levels by an SSB allele in vivo ${ }^{30}$ suggest an interaction between SSB and the topoisomerases.

Our results indicate that SSB specifically stimulates topoisomerase I activity with no detectable effect on DNA gyrase activity. SSB stimulates the first step of the relaxation reaction, i.e. noncovalent interaction between DNA and topoisomerase I. Inhibition of cleavage in the presence of excess SSB, absence of ternary complex in electrophoretic mobility shift assays, gel filtration profiles and optical biosensor studies suggest that the stimulation occurs in the absence of direct proteinprotein communication. A corollary to the functional nature of the cooperation between SSB and topoisomerase I is that we see a similar modulation even when proteins from heterologous sources are used. This is in contrast to the known pattern of interaction between proteins where the homologous partners participate, while the heterologous counterparts do not. For instance SSBs and uracil DNA glycosylases from E. coli and M. tuberculosis do not interact in heterologous combination. ${ }^{22}$ In E. coli, SSB specifies the site of priming activity of DnaG only when homologous SSB is used. ${ }^{12}$ Similarly, a specific physical interaction was demonstrated between ICP8, an SSB homologue in herpes simplex virus, and UL8 subunit of the primase. EcoSSB is unable to substitute for ICP8. ${ }^{21}$

The DNA duplex in the bacterial cell is covalently closed and maintained in an underwound state. This topological state has a higher intrinsic free energy and therefore thermodynamically favors processes that require melting or denaturation of the DNA duplex. The unwinding of the 


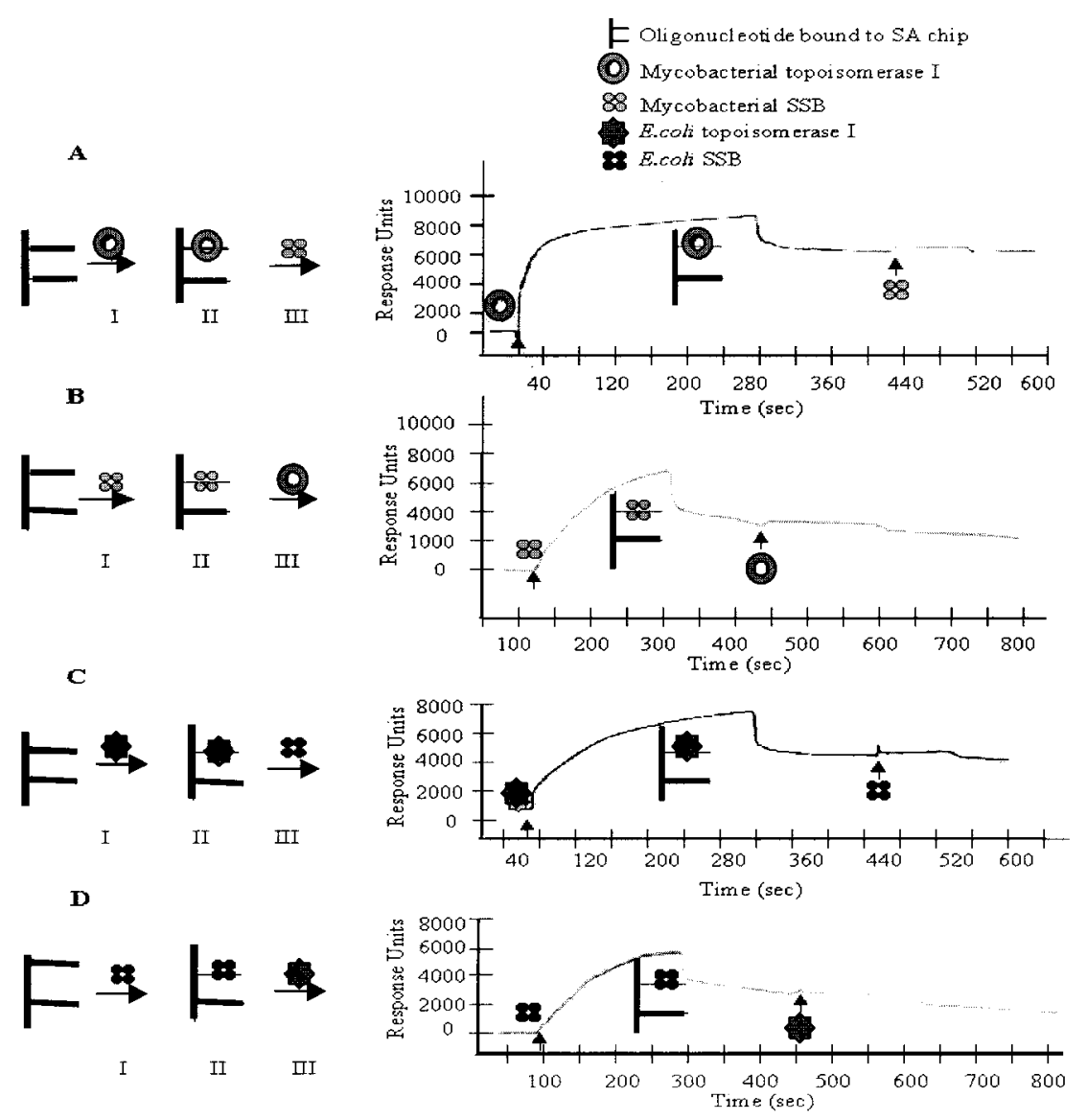

Figure 8. Analysis of topoisomerase I-SSB interaction. The biotinylated oligonucleotides were immobilized on the streptavidin sensor chip. Topoisomerase I $(250 \mathrm{nM})$ and $500 \mathrm{nM}$ SSB were used in the analysis. Arrows indicate the start of each injection. The various steps of the analysis have been shown schematically. In all these analysis, the binary complex (II) was first formed between the DNA (I) and the indicated protein. Subsequently, the other protein (III) was assessed for its ability to form a ternary complex. (a) Interaction of MtubSSB with preformed MsTop-DNA binary complex. (b) Interaction of MsTop with preformed MtubSSB-DNA binary complex. (c) Interaction of EcoSSB with preformed EcoTop-DNA binary complex. (d) Interaction of EcoTop with preformed EcoSSBDNA binary complex.

DNA strands during replication followed by the tracking of the replication machinery generates positive supercoils ahead and negative supercoils behind the fork. ${ }^{31}$ Gyrase, by its ability to introduce negative supercoils, reduces the accumulation of the positive supercoils ahead while topoisomerase $\mathrm{I}$ is believed to reduce the topological strain behind. ${ }^{32}$ SSB facilitates the movement of the fork by maintaining the DNA in a single-stranded state behind the gyrase. Since SSB does not bind to the positively supercoiled DNA, it does not affect the gyrase activity. Due to its large local concentration in the vicinity of the fork and preference for negatively supercoiled, ${ }^{28}$ SSB could bind to the unwound DNA behind the fork stabilizing singlestranded regions. This region could act as a sink to recruit topoisomerase I that can then act efficiently to relieve the strain. The other potent relaxation activity in the cell, topoisomerase IV, ${ }^{33}$ preferentially binds to crossovers in DNA. ${ }^{34}$ Therefore, like gyrase, it would be expected to be unaffected by the presence of SSB. This might explain the partitioning of topoisomerase IV into primarily a decatenation function while topoisomerase I acts as the principal relaxation enzyme and gyrase as the sole supercoiling activity in the cell.

The diverse actions of various topoisomerases are responsible for the maintenance of the homeostatic balance in DNA topology in prokaryotic cells. A question not addressed until recently is the possible interaction of these topoisomerases with other cellular proteins, which would influence their activity. Such influence on topoisomerase activity though not essential, yet may play crucial role in overall balance of DNA topology. Many proteins involved in replication or other important processes could be possible candidates and here we have considered SSB to address this point. We believe that functional cooperation between DNA transaction proteins without direct interaction is a general phenomenon and is not restricted to the SSB-topoisomerase paradigm presented in this manuscript. Research efforts have concentrated mostly on providing evidence on direct interactions and the importance of indirect communications has not been appreciated. Indirect interactions could be amenable for genetic analyses and the SSB-113 allele ${ }^{35}$ appears to be a representative of such mutants.

\section{Materials and Methods}

\section{Purification of topoisomerases}

MsTop was purified as described by Bhaduri \& Nagaraja. ${ }^{36}$ EcoTop overexpressing plasmid was a kind gift from J.C Wang, Harvard University, Cambridge. EcoTop was purified using the method of Lynn and Wang. ${ }^{37}$ E. coli gyrase was purified as described by Maxwell \& Howells. ${ }^{38}$ 


\begin{tabular}{|c|c|c|c|c|c|c|c|c|c|}
\hline 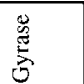 & ' & + & + & + & + & + & + & + & . \\
\hline 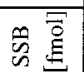 & ' & ' & 8 & 8 & 8 & ళ్ & 8 & 8 & ' \\
\hline
\end{tabular}

(a)
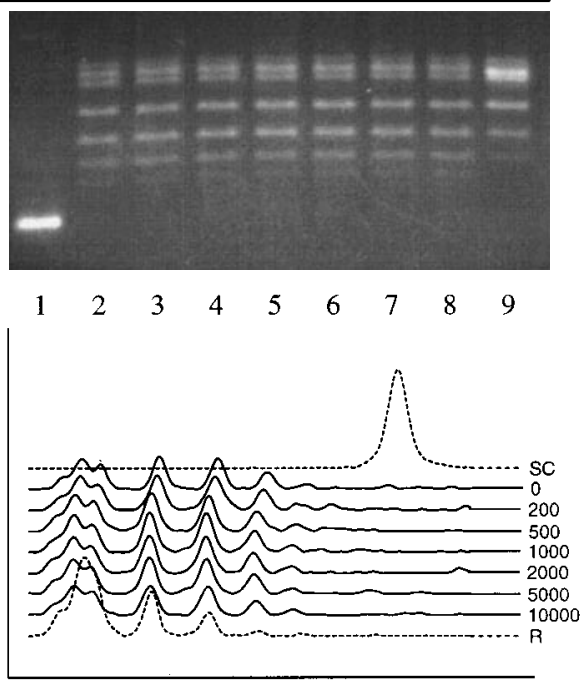

Distance (arbitrary units)

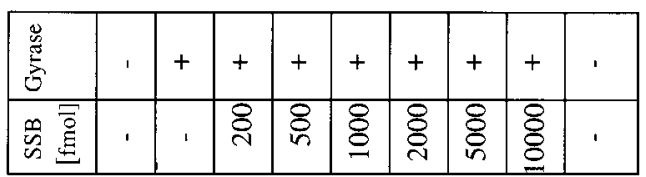

(b)
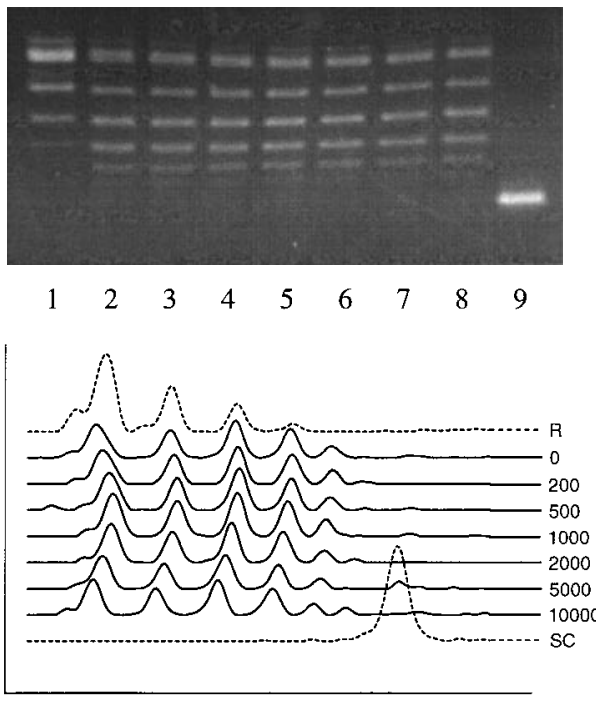

Distance (arbitrary units)

Figure 9. Influence of SSB on E. coli DNA gyrase activity. (a) DNA gyrase relaxation assay, Lane 1, supercoiled pUC18, lane 9, relaxed DNA. Lanes 2-8 supercoiled pUC18 incubated with EcoSSB and DNA gyrase as indicated. The reaction was carried out in the relaxation buffer as described in Materials and Methods. (b) DNA gyrase supercoiling activity, Lane 1, relaxed pUC18; lane 9, supercoiled pUC18; lanes 2-8 relaxed pUC18 incubated with EcoSSB and DNA gyrase as indicated. The reaction was carried out at $37^{\circ} \mathrm{C}$ in the supercoiling buffer as described in Materials and Methods. Densitometric scans of both the reactions are shown.

\section{Single strand binding proteins}

EcoSSB was obtained from Bangalore Genei (P) Ltd. MtubSSB was a generous gift from U. Varshney.

\section{Topoisomerase I relaxation assay}

Ceasium chloride-purified supercoiled pUC18 was used as substrate in the relaxation assay of topoisomerase I. The assay was performed in reaction mix of $20 \mu \mathrm{l}$ containing $40 \mathrm{mM}$ Tris- $\mathrm{HCl}(\mathrm{pH} 8.0), 2.5 \mathrm{mM} \mathrm{MgCl}$, $20 \mathrm{mM} \mathrm{NaCl}, 500 \mathrm{ng}$ of pUC18 and $10 \mathrm{fmol}$ of MsTop. EcoTop mediated relaxation reaction was carried out in $40 \mathrm{mM}$ Tris- $\mathrm{HCl}(\mathrm{pH}$ ) containing $40 \mathrm{mM} \mathrm{NaCl}, 5 \mathrm{mM}$ $\mathrm{MgCl}_{2}$ and $1 \mathrm{mM}$ EDTA. Reactions were stopped after 30 minutes by adding $0.4 \%(\mathrm{w} / \mathrm{v})$ SDS, $8 \%(\mathrm{v} / \mathrm{v})$ Ficoll, and $0.6 \%(\mathrm{w} / \mathrm{v})$ bromophenol blue and resolved on a $1.2 \%$ agarose gel at $1 \mathrm{~V} / \mathrm{cm}$ for 12 hours. The DNA was visualized under UV after staining with ethidium bromide.

\section{DNA gyrase relaxation and supercoiling assays}

Relaxation by DNA gyrase was performed in assay buffer containing Tris- $\mathrm{HCl}(\mathrm{pH} 7.6), 35 \mathrm{mM} \mathrm{KCl}, 25 \mathrm{mM}$ $\mathrm{MgCl}_{2}, 2 \mathrm{mM}$ spermidine, $0.36 \mathrm{mg} / \mathrm{ml}$ bovine serum albumin $9 \mu \mathrm{g} / \mathrm{ml}$ yeast tRNA, $6.5 \%(\mathrm{w} / \mathrm{v})$ glycerol, and $5 \mathrm{mM}$ DTT at $37^{\circ} \mathrm{C}$ for 30 minutes with $500 \mathrm{ng}$ of supercoiled pUC18. The reaction was stopped by adding $4 \mu \mathrm{l}$ of agarose loading dye containing SDS to a final concentration of $0.1 \%$ and heating at $65^{\circ} \mathrm{C}$. The DNA supercoiling reaction conditions were similar to relaxation assay except that relaxed pUC19 was used and $1.4 \mathrm{mM}$ ATP was included in the assay buffer. All reactions contained 0.5 units of DNA gyrase. One unit is defined as the amount of enzyme required to completely supercoil or relax substrate DNA in 30 minutes at $37^{\circ} \mathrm{C}$. The ethidium bromide stained gels were scanned using BIORAD Gel Doc 1000.

\section{Electrophoretic mobility shift assay for covalent complex}

For assessing covalent complex formation a 65-bp HinfI fragment of pUC19 containing STS for the enzyme was isolated as described. ${ }^{19}$ Purified topoisomerase I (20 fmol) was incubated along with 65-bp end-labeled $(25000 \mathrm{cpm})$ DNA fragment in a reaction mixture containing $20 \mathrm{mM}$ Tris- $\mathrm{HCl}$ (pH 8.0), $1 \mathrm{mM}$ EDTA and $20 \mathrm{mM} \mathrm{NaCl}$ in the presence of different concentrations of SSB at $37^{\circ} \mathrm{C}$ for ten minutes. The DNA-protein covalent intermediate was arrested using $25 \mathrm{mM} \mathrm{NaOH}$ and neutralized after five minutes using $25 \mathrm{mM} \mathrm{HCl}$ and $25 \mathrm{mM}$ Tris- $\mathrm{HCl}$ ( $\mathrm{pH}$ 8.0). The complexes were resolved by electrophoresing the reaction products for one hour at $150 \mathrm{~V}$ through urea- $8 \%$ PAGE.

\section{Non-covalent complex}

A 32mer end-labeled DNA (TATTGGGCGCTCTTC CGCTTCCTCGCTCACTG) was annealed to its complementary strand. Non-covalent enzyme-DNA complexes were formed using $40 \mathrm{mM}$ Tris- $\mathrm{HCl}(\mathrm{pH}$ 8.0), $20 \mathrm{mM} \mathrm{NaCl}, 1 \mathrm{mM}$ EDTA, $100 \mathrm{fmol}$ of radiolabeled 32 mer duplex oligonucleotide and $5 \mathrm{fmol}$ of MsTop by incubating on ice for five minutes. The products were resolved by electrophoresing at $150 \mathrm{~V}$ for one hour through native $8 \%(\mathrm{w} / \mathrm{v})$ polyacrylamide gel (30:0.8) 
using $0.5 \times \mathrm{TBE}$ as the running buffer. The radioactivity associated with free and DNA protein complex were estimated by phosphoimager (Fuji film; model BAS 1800).

\section{Assay for unwinding activity of SSB}

Supercoiled plasmid pUC19 was linearized by digesting with BamHI. DNA was extracted with phenol chloroform and precipitated. T4 DNA ligase mediated intramolecular ligation of the DNA was then performed either in the absence or indicated amounts of SSB at $25^{\circ} \mathrm{C}$. Reactions were stopped after eight hours by adding $0.4 \%$ SDS, $8 \%$ Ficoll, and $0.6 \%$ bromophenol blue and resolved on a $1.2 \%$ agarose gel at $1 \mathrm{~V} / \mathrm{cm}$ for 12 hours. The DNA was visualized under UV after staining with ethidium bromide.

\section{Immunoprecipitation}

M. smegmatis topoisomerase I (300 ng) and MtubSSB (300 ng) were co-incubated in $40 \mathrm{mM}$ Tris- $\mathrm{HCl}(\mathrm{pH} 8.0)$ and $50 \mathrm{mM} \mathrm{NaCl}$ for ten minutes followed by the addition of anti-topoisomerase I polyclonal antibodies $(200 \mu \mathrm{g} / \mathrm{ml})$. After incubation for an hour, the immunocomplex was precipitated by the addition of $10 \mu \mathrm{l}$ Protein-G agarose. The protein components in precipitate and supernatant were resolved on $10 \%$ SDS-PAGE and analyzed by silver staining.

\section{Gluteraldehyde crosslinking}

M. smegmatis topoisomerase I (400 ng) and MtubSSB (400 ng) were co-incubated in $40 \mathrm{mM}$ Tris- $\mathrm{HCl}(\mathrm{pH} 8.0)$ and $50 \mathrm{mM} \mathrm{NaCl}$ for ten minutes. Following addition of gluteraldehyde $(0.06 \%)$ the reaction mix was further incubated for ten minutes, resolved on SDS-10\% PAGE and visualized by silver staining.

\section{Gel filtration}

Gel filtration analysis of topoisomerase I and SSB was performed at $8{ }^{\circ} \mathrm{C}$. Reactions containing MsTop (52 $\mu \mathrm{g}$ ) and SSB $(60 \mu \mathrm{g})$ in $100 \mu \mathrm{l}$ were incubated in buffer containing $40 \mathrm{mM}$ Tris- $\mathrm{HCl}(\mathrm{pH} 8.0)$ and $50 \mathrm{mM} \mathrm{NaCl}$ or $150 \mathrm{mM} \mathrm{NaCl}$ for ten minutes and loaded onto Superdex 200 HR gel filtration column (Pharmacia) and eluted at low $(50 \mathrm{mM})$ or high $(150 \mathrm{mM}) \mathrm{NaCl}$. Fractions of $200 \mu \mathrm{l}$ were collected and analyzed in SDS-8\% PAGE.

\section{Surface plasmon resonance}

Monolayers of biotinylated oligonucleotides containing the STS. ${ }^{39}$ were immobilized on a streptavidin chip (SA5). A 20 pmol sample of the 24mer oligonucleotide (5'-biotin-AAGAATTCAGGTACCCGCTTCCAA) suspended in buffer containing $10 \mathrm{mM}$ Hepes ( $\mathrm{pH}$ 7.5), $200 \mathrm{mM} \mathrm{NaCl}$ and $2 \mathrm{mM}$ EDTA was injected in continuous flow to immobilize the oligonucleotides corresponding to about 1000 response units (RU). The flow cell was washed with $20 \mathrm{mM}$ Tris ( $\mathrm{pH} \mathrm{8.0)}$ ), and $10 \mathrm{mM} \mathrm{NaCl}$ for 300 seconds. Topoisomerase I or SSB was immobilized to the DNA by injecting the small aliquots of the protein (125-500 nmol). Regeneration of the surface was achieved by injecting $60 \mu \mathrm{l}$ of pUC19 DNA $(1 \mu \mathrm{g} / \mu \mathrm{l})$. The data obtained was analyzed by BIAevalution program 3.1, using BIAcore2000 (LKB-Pharmacia Biotech).

\section{Acknowledgments}

We thank U. Varshney and P. Handa for the MtubSSB and MtubSSB coated SA5 chip, S. Chandrashekavan for EcoSSB and U.H. Manjunatha for gel filtration analysis. D.S. and T.B. were recipients of JNCASR project assistantships. The research is supported by grants from Department of Biotechnology, Government of India.

\section{References}

1. Wang, J. C. (1991). DNA topoisomerases: why so many? J. Biol. Chem. 266, 6659-6662.

2. Madhusudan, K. \& Nagaraja, V. (1996). Alignment and phylogenetic analysis of type II DNA topoisomerase. J. Biosci. 21, 613-629.

3. Maxwell, A. \& Gellert, M. (1986). Mechanistic aspects of DNA topoisomerases. Advan. Protein Chem. 38, 69-107.

4. Wang, J. C. (1996). DNA topoisomerases. Annu. Rev. Biochem. 65, 635-692.

5. Watt, P. M., Louis, E. J., Borts, R. H. \& Hickson, I. D. (1995). Sgs1: a eukaryotic homolog of E. coli RecQ that interacts with topoisomerase II in vivo and is required for faithful chromosome segregation. Cell, 81, 253-260.

6. Gangloff, S., McDonald, J. P., Bendixen, C., Arthur, L. \& Rothstein, R. (1994). The yeast type I topoisomerase Top3 interacts with Sgs1, a DNA helicase homolog: a potential eukaryotic reverse gyrase. Mol. Cell. Biol. 14, 8391-8398.

7. Wang, X., Watt, P. M., Louis, E. J., Borts, R. H. \& Hickson, I. D. (1996). Pat1: a topoisomerase II-associated protein required for faithful chromosome transmission in Saccharomyces cerevisiae. Nucl. Acids Res. 24, 4791-4797.

8. Gobert, C., Bracco, L., Rossi, F., Olivier, M., Tazi, J., Lavelle, F., Larsen, A. K. \& Riou, J.-R. (1996). Modulation of DNA topoisomerase I activity by p53. Biochemistry, 35, 5778-5786.

9. Nakanishi, A., Oshida, T., Matsushita, T., ImajohOhmi, S. \& Ohnuki, T. (1998). Identification of DNA gyrase inhibitor (GyrI) in Escherichia coli. J. Biol. Chem. 273, 1933-1938.

10. Marians, K. J. (1992). Prokaryotic DNA replication. Annu. Rev. Biochem. 61, 673-719.

11. Yuzhakov, A., Kelman, Z. \& O’Donnell, M. (1999). Trading places on DNA: a three-point switch underlies primer handoff from primase to the replicative DNA polymerase. Cell, 96, 153-163.

12. Sun, W. \& Godson, G. N. (1996). Interaction of Escherichia coli primase with a phage G4ori(c)-E. coli SSB complex. J. Bacteriol. 178, 6701-6705.

13. Lu, Y. B., Ratnakar, P. V., Mohanty, B. K. \& Bastia, D. (1996). Direct physical interaction between DnaG primase and DnaB helicase of Escherichia coli is necessary for optimal synthesis of primer RNA. Proc. Natl Acad. Sci. USA, 93, 12902-12907.

14. Manna, A. C., Pai, K. S., Bussiere, D. E., Davies, C., White, S. W. \& Bastia, D. (1996). Helicase-contrahelicase interaction and the mechanism of termination of DNA replication. Cell, 87, 881-91.

15. Umezu, K. \& Kolodner, R. D. (1994). Protein interactions in genetic recombination in Escherichia coli. Interactions involving $\mathrm{RecO}$ and $\mathrm{Rec}$ overcome the 
inhibition of RecA by single-stranded DNA-binding protein. J. Biol. Chem. 269, 30005-30013.

16. Anderson, D. G. \& Kowalczykowski, S. C. (1998). SSB protein controls RecBCD enzyme nuclease activity during unwinding: a new role for looped intermediates. J. Mol. Biol. 282, 275-285.

17. Kowalczykowski, S. C. \& Eggleston, A. K. (1994). Homologous pairing and DNA strand-exchange proteins. Annu. Rev. Biochem. 63, 991-1043.

18. Sarov-Blat, L. \& Livneh, Z. (1998). The mutagenesis protein MucB interacts with single strand DNA binding protein and induces a major conformational change in its complex with single-stranded DNA. J. Biol. Chem. 273, 5520-5527.

19. Bhaduri, T., Sikder, D. \& Nagaraja, V. (1998). Sequence specific interaction of Mycobacterium smegmatis topoisomerase I with duplex DNA. Nucl. Acids Res. 26, 1668-1674.

20. Clendenning, J. B. \& Schurr, J. M. (1994). A model for the binding of E. coli single-strand binding protein to supercoiled DNA. Biophys. Chem. 52, 227-49.

21. Falkenberg, M., Bushnell, D. A., Elias, P. \& Lehman, I. R. (1997). The UL8 subunit of the heterotrimeric herpes simplex virus type 1 helicase-primase is required for the unwinding of single strand DNAbinding protein (ICP8)-coated DNA substrates. J. Biol. Chem. 272, 22766-22770.

22. Purnapatre, K., Handa, P., Venkatesh, J. \& Varshney, U. (1999). Differential effects of singlestranded DNA binding proteins (SSBs) on uracil DNA glycosylases UDGs) from Escherichia coli and mycobacteria. Nucl. Acids Res. 27, 3487-3492.

23. Miller, A., Wood, D., Ebright, R. H. \& RothmanDenes, L. B. (1997). RNA polymerase beta subunit: a target of DNA binding-independent activation. Science, 275, 1655-1657.

24. Sandigursky, M., Mendez, F., Bases, R. E., Matsumoto, T. \& Franklin, W. A. (1996). Proteinprotein interactions between the Escherichia coli single-stranded DNA-binding protein and exonuclease I. Radiat. Res. 145, 619-623.

25. Hegde, S. P., Qin, M. H., Li, X. H., Atkinson, M. A., Clark, A. J., Rajagopalan, M. \& Madiraju, M. V. (1996). Interactions of RecF protein with $\mathrm{RecO}$, RecR, and single-stranded DNA binding proteins reveal roles for the RecF-RecO-RecR complex in DNA repair and recombination. Proc. Natl Acad. Sci. USA, 93, 14468-144773.

26. Kowalczykowski, S. C. \& Krupp, R. A. (1987). Effects of Escherichia coli SSB protein on the singlestranded DNA-dependent ATPase activity of Escherichia coli RecA protein. Evidence that SSB protein facilitates the binding of RecA protein to regions of secondary structure within single-stranded DNA. J. Mol. Biol. 193, 97-113.

27. Seo, Y. S. \& Hurwitz, J. (1993). Isolation of helicase alpha, a DNA helicase from HeLa cells stimulated by a fork structure and signal-stranded DNAbinding proteins. J. Biol. Chem. 268, 10282-10295.

28. Langowski, J., Benight, A. S., Fujimoto, B. S., Schurr, J. M. \& Schomburg, U. (1985). Change of conformation and internal dynamics of supercoiled DNA upon binding of Escherichia coli single-strand binding protein. Biochemistry, 24, 4022-4028.

29. Srivenugopal, K. S. \& Morris, D. R. (1986). Modulation of the relaxing activity of Escherichia coli topoisomerase I by single-stranded DNA-binding proteins. Biochem. Biophy Res. Commun. 137, 795-800.

30. Quinones, A. \& Neumann, S. (1997). The ssb-113 allele suppresses the dnaQ49 mutator and alters DNA supercoiling in Escherichia coli. Mol. Microbiol. 25, 237-246.

31. Liu, L. F. \& Wang, J. C. (1987). Supercoiling of the DNA template during transcription. Proc. Natl Acad. Sci. USA, 84, 7024-7027.

32. Tsao, Y. P., Wu, H. Y. \& Liu, L. F. (1989). Transcription-driven supercoiling of DNA: direct biochemical evidence from in vitro studies. Cell, 56, 111-118.

33. Zechiedrich, E. L., Khodursky, A. B. \& Cozzarelli, N. R. (1997). Topoisomerase IV, not gyrase, decatenates products of site-specific recombination in Escherichia coli. Genes Dev. 11, 2580-2592.

34. Roca, J., Berger, J. M. \& Wang, J. C. (1993). On the simultaneous binding of eukaryotic DNA topoisomerase II to a pair of double-stranded DNA helices. J. Biol. Chem. 268, 14250-14255.

35. Chase, J. W., L'Italien, J. J., Murphy, J. B., Spicer, E. K. \& Williams, K. R. (1984). Characterization of the Escherichia coli SSB-113 mutant single-stranded DNA-binding protein. Cloning of the gene, DNA and protein sequence analysis, high pressure liquid chromatography peptide mapping, and DNAbinding studies. J. Biol. Chem. 259, 805-14.

36. Bhaduri, T. \& Nagaraja, V. (1994). DNA topoisomerase I from Mycobacterium smegmatis. Indian J. Biochem. Biophys. 31, 339-43.

37. Lynn, R. M. \& Wang, J. C. (1989). Peptide sequencing and site-directed mutagenesis identify tyrosine319 as the active site tyrosine of Escherichia coli DNA topoisomerase I. Proteins: Struct. Funct. Genet. 6, 231239.

38. Maxwell, A. \& Howells, A. J. (1999). Overexpression and purification of bacterial DNA gyrase. In DNA Topoisomerase Protocols, Volume 1: DNA Topology and Enzymes (Bjornsti, M.-A. \& Osheroff, N., eds), pp. 135-144, Humana Press Inc., Totowa, NJ. 